\title{
Síndrome de mononucleosis infecciosa en pacientes adolescentes y adultos
}

\author{
ALBERTO FICA C. ${ }^{1}$
}

\section{Infectious Mononucleosis syndrome in adolescents and adult patients}

Infectious mononucleosis syndrome, characterized in typical cases by fever, sore throat, tonsillar exudates, cervical adenopathies and atypical lymphocytosis is associated in most cases to Epstein-Barr virus (EBV) infection. Other potential causes for this syndrome are acute cytomegalovirus (CMV), Human Immunodeficiency Virus, Toxoplasma gondii or Human Herpes virus 6 infection. These alternative etiologies evolve with a modified clinical picture that includes sometimes leukopenia or rash. Diagnosis of EBV is easily accomplished by atypical lymphocytosis (> 10\%), positive heterophil antibodies and IgM antibodies directed against the EB viral capsid antigen (VCA). The latter is needed for cases without positive heterophil antibodies. Acute CMV infection is the second most important cause and can be diagnosed by CMV antigen detection, PCR or shell vial culture of blood samples, although experience with these tests among immunocompetent patients in primary care settings is sparse. Acute primary HIV infection is an important cause for this syndrome and should not be neglected when other causes are discarded. Third or fourth generation HIV ELISA tests, p24 antigen or HIV-PCR detection in blood samples allow recognition of this agent from the second or third week of inoculation. T. gondii and human herpes virus 6 infection can be diagnosed by serological methods. Evolution of EBV or CMV infection is favorable with infrequent complications.

Key words: Infectious mononucleosis syndrome; Diagnosis.

\section{Introducción}

El síndrome de mononucleosis infecciosa se caracteriza en grado variable por la presencia de fiebre de inicio reciente, odinofagia (con o sin exudado faríngeo), adenopatías cervicales y en los casos característicos, por linfocitosis atípica ${ }^{1}$.

Diferentes condiciones han sido asociadas a este síndrome (Tabla 1), aunque más del $80 \%$ de los casos puede ser atribuido a la infección aguda por $\mathrm{VEB}^{1}$. Las causas tradicionales del síndrome incluyen la infección por VEB, CMV, la primoinfección por $\mathrm{VIH}$, la infección aguda por Toxoplasma gondii en pacientes inmunocompetentes y las infecciones por virus herpes humano $6^{1}$ (Tabla 1). Sin embargo, esta lista puede aumentar o disminuir sí se incluye o no el criterio de linfocitosis atípica y la duración de la fiebre. Por ejemplo, las infecciones agudas por adeno- virus, Corynebacterium diphtheriae, Streptococcus pyogenes, virus influenza A y $\mathrm{B}$, rubéola, hepatitis A y Coxiella burnetti, participan en el diagnóstico diferencial durante los primeros días de evolución (ver más adelante) ${ }^{1}$.

\section{Causas específicas de síndrome de mononucleosis infecciosa}

Infección aguda por virus de Epstein Barr. La infección aguda por este agente es frecuente y generalmente asintomática o inespecífica en los menores de edad y ha sido relacionada con el nivel socioeconómico de una población. Los pacientes adolescentes o adultos jóvenes que permanecen susceptibles, desarrollan tradicionalmente el cuadro de mononucleosis infecciosa (MI). La infección se adquiere mediante transmisión de secreciones orofaríngeas y, luego de un período de incubación de 30 a 50 días, la enfermedad se

\footnotetext{
Sección de Infectología, Departamento de Medicina, Hospital Clínico Universidad de Chile.
} 
Tabla 1. Agentes o condiciones asociadas al síndrome de mononucleosis infecciosa

\begin{tabular}{lc}
\hline \multicolumn{1}{c}{ Agente específico } & Proporción de los casos \\
\hline - Virus Epstein-Barr (VEB) & $80-90 \%$ \\
- Citomegalovirus (CMV) & $5-7 \%$ \\
- Primoinfección VIH & Infrecuente \\
- Toxoplasma gondii & Infrecuente \\
- Virus herpes humano 6 (VHH-6) & Infrecuente \\
\hline
\end{tabular}

expresa clínicamente en más de $70 \%$ de los adolescentes expuestos.

Característicamente, la MI asociada al VEB se presenta con un cuadro febril de magnitud variable de varios días de duración (2 a 3 semanas), faringitis asociada a exudado en $\sim 30 \%$ de los casos y adenopatías cervicales anteriores y posteriores. Durante la fase prodrómica se observa decaimiento, anorexia, fatigabilidad, cefalea y fiebre. Los síntomas alcanzan habitualmente su mayor intensidad al final de la primera semana y declinan progresivamente durante las próximas semanas (1 a 3 semanas). La frecuencia de esplenomegalia es variable con detección al examen físico en más de $17 \%$ de los pacientes y en estudios por imágenes en cerca de $100 \%$.

Las manifestaciones infrecuentes de la MI asociada a VEB incluyen obstrucción de la vía aérea, dolor abdominal, exantema, hepatomegalia, ictericia y edema palpebral. El exantema ocurre en aproximadamente 5\% de los pacientes pudiendo ser de tipo macular, petequial, escarlatiniforme, urticarial o eritema multiforme. Adicionalmente, en 90 a 100\% de los pacientes que han recibido ampicilina en los 10 días precedentes se observa un exantema máculopapular.

Los pacientes afectados presentan una linfocitosis $\geq 50 \%$ y un recuento de linfocitos atípicos $\geq 10 \%$ (criterios de Hoagland). Sin embargo, la sensibilidad de estos criterios es limitada y no supera el 66 y $74 \%$, respectivamente. La especificidad es cercana a 80 y $90 \%$, respectivamente $^{2}$. Más de $50 \%$ de los casos tiene trombocitopenia y otro $3 \%$ presenta anemia hemolítica, en ambos casos de tipo leve.

La infección aguda por VEB se establece en linfocitos B, gatillando la estimulación y producción de una diversidad de anticuerpos dirigidos contra el propio VEB y otros antígenos no relacionados tales como eritrocitos de otras especies mamíferas (sin exposición previa), o ampicilina o plaquetas. Los anticuerpos dirigidos a antígenos de otras especies se denominan anticuerpos heterófilos y pueden ser detectados mediante pruebas de aglutinación utilizando eritrocitos de cordero (reacción de Paul-Bunnell) o mediante una diversidad de sistemas comerciales que utilizan pruebas de aglutinación con eritrocitos o partículas de látex. Los preparados disponibles difieren en su sensibilidad y especificidad, siendo en general mejor la sensibilidad con eritrocito de caballo (Tabla 2). Estos anticuerpos aparecen progresivamente durante la primera semana de enfermedad por lo que su positividad es mayor después de este período (Figura 1). Los falsos positivos son infrecuentes y explicados por casos de linfoma, hepatitis viral o enfermedades autoinmunes.

La presencia de linfocitosis $\geq 50 \%$, linfocitosis atípica $\geq 10 \%$ y anticuerpos heterófilos positivos mediante cualquier técnica disponible, permiten reconocer acertadamente los casos de MI provocados por el VEB (Figura 1).

Los anticuerpos de tipo IgM contra la cápside viral (IgM VCA-viral capside antigen) se desarrollan durante el período de incubación y están presentes al inicio de la enfermedad. En casos de anticuerpos heterófilos negativos, la solicitud de IgM VCA permite detectar un porcentaje adicional de casos.

Para confirmar en forma inequívoca un cuadro agudo de MI por VEB, la presencia de IgM VCA debe estar asociada a la ausencia de anticuerpos anti EBNA-Epstein Barr nuclear antigen (Figura 1) y además descartar una infección por CMV debido a la existencia de valores IgM VCA falsamente elevados en esta última condición ${ }^{3}$. Sin embargo, esta precisión diagnóstica es probablemente de escasa relevancia en la atención de pacientes inmunocompetentes en atención primaria que se presentan con un cuadro clínico característico asociado a anticuerpos heterófilos o valores de IgM VCA positivos. La infección antigua para VEB se establece por la detección de anticuerpos IgG-VCA.

La ausencia de anticuerpos heterófilos y de IgM-VCA, permite descartar razonablemente MI por VEB y obliga a plantear otra etiología. 
Tabla 2. Criterios diagnósticos para mononucleosis infecciosa asociada a virus Epstein Barr

\section{Criterios}

- Fiebre, odinofagia, adenopatías cervicales

- $\quad$ Linfocitosis $\geq 50 \%$

- Linfocitosis atípica ${ }^{3} 10 \%$

- Anticuerpos heterófilos

- Cuadro clínico característico, linfocitosis, linfocitosis atípica y anticuerpos heterófilos positivos

- IgM VCA (viral capside antigen)

- Cuadro clínico asociado a IgM VCA (+) y valores negativos para anticuerpos anti EBNA (Epstein-Barr nuclear antigen)

\section{Comentarios}

- Permiten establecer la sospecha de MI en pacientes adolescentes o adultos jóvenes

- Sensibilidad $66 \%$, especificidad $80 \%$

- Sensibilidad $74 \%$, especificidad $90 \%$

- Varias pruebas disponibles con sensibilidad de 63 a $84 \%$ y especificidad de 84 a $100 \%$. Su positividad aumenta después de la primera semana de enfermedad.

- En atención primaria, esta asociación permite establecer el diagnóstico de MI por VEB

- Permite la detección de casos de MI asociados a VEB con anticuerpos heterófilos negativos

- Estándar de oro para confirmación de infección aguda por VEB. Sin embargo, la solicitud de anti-EBNA no es clínicamente necesaria en la mayor parte de los casos

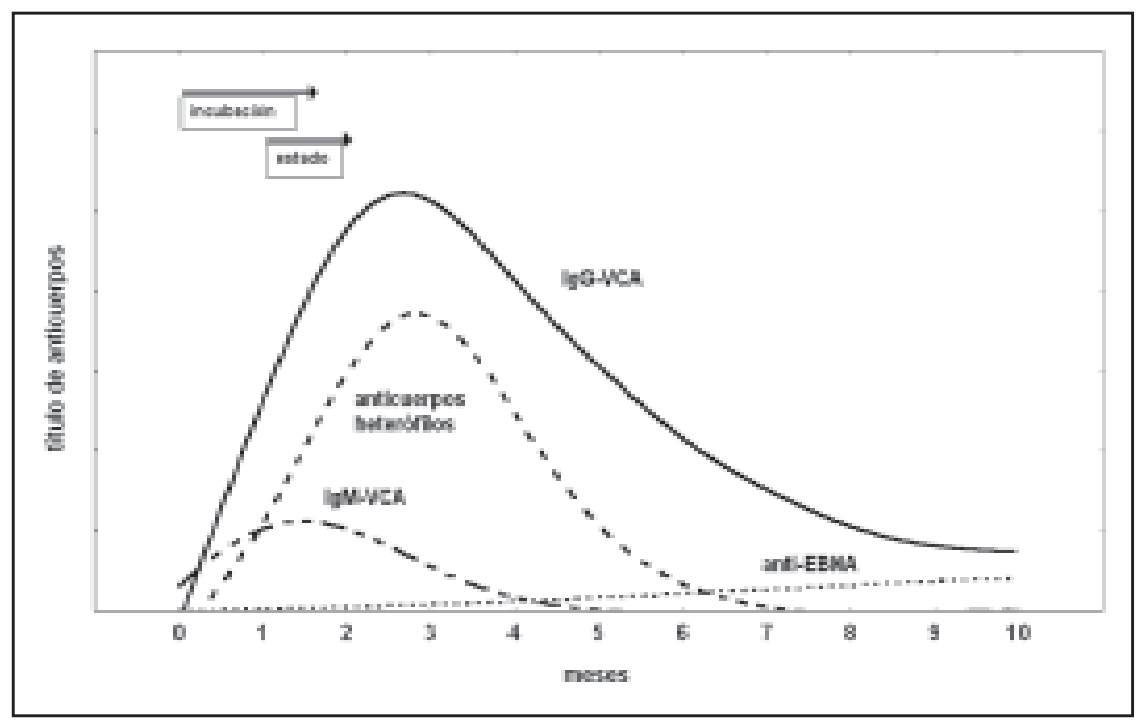

Figura 1.

Los pacientes afectados por MI asociada al VEB no requieren intervenciones terapéuticas específicas. El cuadro es bien tolerado y tiene una baja frecuencia de complicaciones. Ensayos efectuados con aciclovir en altas dosis ( 3 a 4 gramos diarios durante 5 a 7 días), han logrado demostrar una reducción de la excreción viral en secreciones respiratorias, pero su efecto es temporal y sin una mejoría clínica asociada ${ }^{4}$. De la misma manera, los ensayos con corticosteroides orales han demostrado un efecto limitado e in- constante para reducir la fiebre o los síntomas faríngeos y no tienen impacto sobre la evolución de las adenopatías o la esplenomegalia. Su uso no se recomienda, excepto en casos de obstrucción faucial ${ }^{1,4}$.

Esta enfermedad tiene en la mayor parte de los casos una evolución benigna y los pacientes deben recibir sólo manejo sintomático y ser advertidos de potenciales complicaciones, las que son en general muy infrecuentes ${ }^{4}$ (Tabla 3 ). La rotura espontánea del bazo es un hecho infrecuente en 
Tabla 3. Indicaciones generales para los pacientes afectados por mononucleosis infecciosa

- Manejo sintomático

- Evitar actividades con riesgo de traumatismo

- Las precauciones deben seguirse por un mes

- Advertir al paciente del riesgo de rotura esplénica y/o otras complicaciones y la necesidad de una consulta precoz

Algunas complicaciones asociadas al síndrome de mononucleosis infecciosa asociada al VEB

- Hematológicas: anemia hemolítica, trombocitopenia, granulocitopenia, anemia aplástica

- Neurológicas: encefalitis, mielitis transversa, síndrome de Guillain-Barré, parálisis facial periférica, neuritis óptica

- Cardíacas: miocarditis, pericarditis

- Respiratorias: obstrucción laringotonsilar, neumonía, pleuritis, linfoadenopatía hiliar, carcinoma nasofaríngeo

- Dermatológicas: exantema asociado a ampicilina, vasculitis leucocitoclástica, acrocianosis

- Renales: nefritis intersticial, glomerulonefritis

- Hepáticas: hepatitis, necrosis hepática masiva, síndrome de Reye

- Esplénica: rotura

- Inmunológicas: anergia, hipogamaglobulinemia

Tabla 4. Presentación clínica de la rotura esplénica en mononucleosis infecciosa

- Dolor súbito en hipocondrio izquierdo

- En ocasiones se asocia a omalgia izquierda que aumenta durante la inspiración (signo de Kher)

- Masa palpable en hipocondrio izquierdo

- Elevación leve de las transaminasas

Nota: Complicación muy infrecuente, afecta a adolescentes y adultos jóvenes.

la evolución de la MI. Su frecuencia alcanza aproximadamente al $0,1 \%$ y se presenta como un cuadro de dolor abdominal agudo (Tabla 4$)^{5}$. No se han registrado casos de rotura en pacientes sin esplenomegalia. El aumento de tamaño de este órgano se prolonga durante un mes.

Infección aguda por citomegalovirus (CMV). Los cuadros clínicos asociados a las infecciones por este agente son diversas, aunque la mayor parte de las veces la infección es subclínica. No sólo se asocia a cuadros de MI, sino que también al síndrome TORCH en casos de transmisión vertical y a una diversidad de cuadros en pacientes inmunocomprometidos. El síndrome de MI por CMV también afecta a adolescentes y adultos, aunque se presenta en un rango más amplio de edad y más del $40 \%$ de los casos ocurre sobre los 30 años. La presencia de faringitis, adenopatías o esplenomegalia es infrecuente. La fiebre habitualmente es más prolongada y en algunos casos puede alcanzar los 4 meses de duración. Aproximadamente un tercio de los casos de MI no asociados a VEB son provocados por CMV (57\%, Tabla 1).

El diagnóstico de MI asociada a CMV debe plantearse en aquellos casos donde se ha descar- tado una infección aguda por VEB (ausencia de anticuerpos heterófilos y títulos negativos para IgM-VCA). Numerosas alternativas se encuentran disponibles para el diagnóstico de las infecciones por CMV y ellas incluyen serología, antigenemia viral, cultivo viral y amplificación de material genético ${ }^{6}$.

El estudio serológico tiene el inconveniente de requerir muestras pareadas para demostrar una seroconversión y está limitado por la persistencia prolongada de anticuerpos IgM CMV luego de la infección inicial que impide establecer la antigüedad de la infección (Tabla 5).

La detección de antígenos virales en leucocitos mononucleares mediante anticuerpos monoclonales dirigidos a antígenos precoces (antigenemia), ofrece la ventaja de un diagnóstico rápido (1 a 2 días) aunque a un costo elevado. La sensibilidad y especificidad de este examen ha superado el $90 \%$ en algunas evaluaciones ${ }^{7}$, aunque estos mismos parámetros no han sido reproducidos en otros ensayos, revelando cifras de sensibilidad inferiores al $60 \%{ }^{6}$. El cultivo o aislamiento viral tiene el inconveniente de una espera prolongada (hasta 6 semanas) y la necesidad de laboratorios de acceso restringido. Modificaciones en las técnicas de cultivo acopladas a una detección de antígenos precoces (shell vial culture) permiten la identificación en plazos menores. Sin embargo, la sensibilidad reportada de esta estrategia es muy baja $(<30 \%)^{6}$.

La amplificación génica de fragmentos de ADN de CMV mediante la reacción de polimerasa en cadena (RPC) tiene una alta sensibilidad para la detección de este agente durante el primer mes de evolución, pero tiene el inconveniente de la persistencia de resultados positivos en el tiempo (20\% a los 6 meses) lo que disminuye su valor predictor positivo ${ }^{6}$. 
Tabla 5. Estrategias diagnósticas para el reconocimiento de mononucleosis infeccciosa asociada a citomegalovirus

\begin{tabular}{lll}
\hline \multicolumn{1}{c}{ Estrategia } & \multicolumn{1}{c}{ Comentarios } \\
\hline - Detección anticuerpos IgG-CMV & $\begin{array}{l}\text { Útil en casos de seroconversión, requiere muestras pa- } \\
\text { readas }\end{array}$ \\
- Detección anticuerpos IgM-CMV & $\begin{array}{l}\text { Falsos positivos por prevalencia de infección asinto- } \\
\text { mática en la población y persistencia de títulos por } \\
\text { tiempos prolongados }\end{array}$ \\
- Antigenemia CMV & $\begin{array}{l}\text { Resultados disponibles en forma rápida. Alta sensibi- } \\
\text { lidad y especificidad en estudios iniciales. Potencial- } \\
\text { mente limitado por bajos niveles de antigenemia en } \\
\text { población inmunocompetente }\end{array}$ \\
$\begin{array}{ll}\text { - Cultivo viral } \\
\text { Detección precoz de antígenos en cultivos virales } \\
\text { shell vial culture) }\end{array}$ & $\begin{array}{l}\text { Lenta disponibilidad de resultados } \\
\text { Amplificación de fragmentos génicos mediante RCP } \\
\text { Especificidad desconocida }\end{array}$ \\
& $\begin{array}{l}\text { Alta sensibilidad, probable limitación en la especifici- } \\
\text { dad por persistencia de ADN de CMV en leucocitos } \\
\text { circulantes }\end{array}$ \\
\hline
\end{tabular}

La mejor aproximación para el reconocimiento de pacientes con MI asociada a CMV, aún no se encuentra delineada para el escenario de trabajo propio de la consulta ambulatoria. Por ahora el examen de mayor rendimiento, rapidez y disponibilidad es el estudio de antigenemia. Se puede considerar la existencia de una MI provocada por CMV cuando existe un cuadro clínico sugerente asociado a resultados positivos para este examen o un estudio de RPC, o una seroconversión de IgG para CMV.

Debido a la buena evolución global de esta infección en pacientes inmunocompetentes, los pacientes con $\mathrm{MI}$ asociada a CMV no requieren una terapia antiviral específica. En aquellos casos con manifestaciones muy severas, tales como miocarditis, colitis por CMV u otras formas, se pueden utilizar ganciclovir endovenoso (con el paciente hospitalizado).

Primoinfección por virus de inmunodeficiencia humana. La magnitud relativa de la primoinfección por VIH en los pacientes con síndrome de MI es desconocida. Sin embargo, parece ser infrecuente en términos generales al igual que lo acontecido con los casos asociados a T. gondii y VHH 6.

Además, de las manifestaciones que caracterizan al síndrome de MI, estos pacientes presentan con frecuencia exantema, artralgias, ulceraciones en la mucosa oral y en ocasiones diarrea, náuseas o vómitos ${ }^{8}$. Las manifestaciones clínicas se presentan en forma aguda luego de un período de incubación de 2 a 4 semanas en promedio. Estos pacientes pueden presentar adenopatías occipitales y esplenomegalia. El exantema se prolonga por aproximadamente 7 días, es de tipo macular o máculo-papular y es predominante sobre la región del tronco, cuello y cara. Las lesiones no son pruriginosas.

Los pacientes afectados por VIH presentan cifras más bajas de leucocitos totales en comparación a las otras causas, con una clara tendencia a la leucopenia o franca leucopenia. Asimismo, presentan trombocitopenia y elevación de las enzimas hepáticas ${ }^{8}$.

El diagnóstico se sospecha con baja frecuencia debido a la omisión para pesquisar factores de riesgo para enfermedades de transmisión sexual (ETS). En esta etapa, el diagnóstico se puede establecer mediante alguna de las siguientes alternativas: amplificación por RPC la que resulta positiva desde el décimo día de infección; detección del antígeno p24, presente aproximadamente desde el día 16; test de ELISA de tercera generación (positivo después de la tercera semana) o test de ELISA de cuarta generación, técnica que combina la pesquisa de anticuerpos con la detección del antígeno p24 y que permite la identificación de la infección desde los 16 días9. Debido al período de ventana asociado a esta etapa, la solicitud de pruebas de ELISA de primera o segunda generación no puede ser aplicada, a no ser que se realicen en forma tardía. La solicitud de una carga viral para VIH no se considera apropiada para establecer el diagnóstico debido al riesgo de contaminación durante la amplifica- 
ción. Cualquier resultado positivo en estas pruebas debe ser adecuadamente confirmado.

No existe aún consenso sobre el inicio del tratamiento antiretroviral en esta etapa de la infección por VIH. En general el tratamiento es diferido varios años hasta que ciertos criterios cuantitativos se cumplan. En cualquier caso, estos pacientes debe ser advertidos de su contagiosidad y adoptar medidas de precaución para evitar la transmisión a contactos sexuales o la adquisición de nuevas formas de ETS. Estos pacientes deben ser evaluados por la posibilidad de otras ETS ya adquiridas, seguir bajo control médico regular y recibir educación y algunas inmunizaciones.

Toxoplasma gondii. La mayor parte de las infecciones por este protozoo son asintomáticas, constituyendo una rara causa del síndrome de MI. El agente en pacientes adolescentes o adultos es adquirido por vía oral desde una diversidad de fuentes, incluyendo alimentos contaminados. Los pacientes inmunocompetentes pueden presentar un cuadro de MI asociado en ocasiones con exantema máculo-papular y linfocitosis atípica de baja cuantía $(<10 \%)$. El cuadro tiende a ser más prolongado que lo observado con los otros agentes y puede presentarse con linfoadenopatías localizadas o difusas como la forma clínica predominante. Estas adenopatías son indoloras y generalmente $<3 \mathrm{~cm}$.

El diagnóstico de esta infección se apoya generalmente en métodos serológicos y ocasionalmente en el estudio histológico ganglionar (patognomónico) cuando se presenta como la manifestación clínica predominante. Múltiples pruebas serológicas se encuentran disponibles y ellas están orientadas a pesquisar anticuerpos del tipo $\operatorname{IgG}, \operatorname{IgM}$ o del tipo IgA.

El objetivo central de cualquier estudio debe ser discriminar entre infección antigua (frecuente en la población) versus infección reciente y por ello se recomienda la solicitud simultánea de anticuerpos tipo IgG e IgM para $T$. gondii (Tabla 6). Los anticuerpos IgG aparecen desde la segunda semana, alcanzan títulos máximos a las 6-8 semanas y luego declinan en 1 a 2 años, aunque persisten positivos por el resto de la vida. Debido a la persistencia de los títulos IgM por varios meses, su detección aislada impide el diagnóstico de infección reciente. La infección aguda puede establecerse por seroconversión para anticuerpos IgM o IgG o aumento en los títulos de este último (Tabla 6).

El tratamiento de los pacientes afectados no es necesario en general, excepto ante la presencia de compromiso visceral, síntomas severos o persistencia de ellos. El tratamiento consiste en la administración de sulfadiazina (4 g/día fraccionado en 4 dosis), pirimetamina ( $25 \mathrm{mg} /$ día) y ácido folínico (10-20 mg/día) por 2 a 4 semanas.

Infección por virus herpes humano 6 (VHH-6). Reconocida como una rara causa de MI en pacientes adolescentes o adultos, su diagnóstico se establece mediante estudios serológicos (seroconversión IgM). Sin embargo, para un reconocimiento apropiado de esta etiología se debe descartar previamente una infección por CMV y/o la presencia de factor reumatoideo, debido a que ambas condiciones están asociadas a valores falsamente positivos de IgM para VHH-6 ${ }^{10}$. Al igual que la infección por VEB o CMV, esta infección se asocia a una leve alza de las transaminasas ${ }^{10}$.

\section{Diagnóstico diferencial con otras causas}

Como se señaló, las infecciones por adenovirus (ADV), Corynebacterium diphtheriae, Streptococcus pyogenes, virus influenza (FLU) A y B, rubéola, hepatitis A y otras infecciones pueden simular un síndrome de MI en forma ocasional ${ }^{1}$.

Tabla 6. Estudios serológicos para Toxoplasma gondii

\begin{tabular}{|c|c|}
\hline Estudio serológico y condición & Comentarios \\
\hline - Serología IgG & $\begin{array}{l}\text { - Señala infección antigua en general, aunque la serocon- } \\
\text { versión o el aumento de títulos puede ser utilizado } \\
\text { para determinar una infección aguda. Varias alternati- } \\
\text { vas disponibles tales como reacción de Sabin-Feldman, } \\
\text { ELISA o IFI }\end{array}$ \\
\hline - Serología IgM & $\begin{array}{l}\text { - Su detección aislada impide señalar infección reciente } \\
\text { debido a su persistencia por varios meses }(>12)\end{array}$ \\
\hline - Infección aguda & $\begin{array}{l}\text { - Documentada serológicamente por la seroconversión } \\
\text { con anticuerpos IgG o IgM o un aumento de títulos } \\
\text { de } 2 \text { o más diluciones }\end{array}$ \\
\hline
\end{tabular}


Influenza y adenovirus. Las infecciones respiratorias por ADV o FLU se presentan como una infección aguda. El diagnóstico de influenza está basado en la presencia de un cuadro febril agudo asociado a dos o más de los siguientes síntomas: mialgias, tos, odinofagia y cefalea. La sensibilidad de este criterio es $100 \%$ pero su especificidad es sólo $58 \%{ }^{11}$. La influenza se observa en general en una temporada característica por 8 a 10 semanas, en Chile desde abril o mayo de cada año. Si existe disponibilidad, se puede solicitar un estudio de muestra respiratoria mediante enzima inmunoensayo o ensayo colorimétrico, los que permiten resultados en menos de una hora con una sensibilidad aproximada de $67 \%$ y una especificidad superior a $90 \%{ }^{11}$. Adenovirus puede provocar neumonía, una infección respiratoria alta inespecífica, fiebre faringoconjuntival o queratoconjuntivitis epidémica. El compromiso conjuntival puede ayudar al diagnóstico. Al igual que influenza, se puede establecer el diagnóstico de la infección por ADV mediante pruebas rápidas con muestras respiratorias ${ }^{12}$.

Corynebacterium diphtheriae. Esta enfermedad es actualmente muy infrecuente en Chile gracias a la cobertura del programa ampliado de inmunizaciones. Es de inicio agudo con fiebre de baja magnitud, odinofagia y leve inflamación faríngea con desarrollo de una pseudomembrana gris y adherente, no desplazable. Se debe sospechar esta condición si se observa algunos de los siguientes hechos: pseudomembarana que compromete úvula y paladar blando, adenopatía, edema cervical y faringitis pseudomembranosa asociada a gran toxicidad general, presencia de disfonía y estridor, parálisis del paladar y descarga nasal sanguinolenta con pseudomembrana mucosa asociada ${ }^{13}$.

Streptococcus pyogenes. No más de $15 \%$ de los adultos que consultan por odinofagia y fiebre tienen faringitis estreptocóccica. En caso de sospecha se debe solicitar una prueba rápida para este agente o un cultivo faríngeo. Los elementos que orientan a esta etiología incluyen odinofagia de inicio súbito, fiebre, exudado amigdalino bilateral, petequias en el paladar blando, adenopatía sensible en cadena cervical anterior y/o exantema escarlatiniforme. La exposición a un caso en las últimas dos semanas también aumenta la probabilidad diagnóstica ${ }^{13}$.

Rubéola. Esta enfermedad exantemática viral se encuentra epidemiológicamente controlada en nuestro país desde la campaña de inmunización complementaria que se efectuó en $1999^{14}$. Tiene un período prodrómico breve con fiebre, cefalea, coriza y conjuntivitis antes de que aparezca el exantema morbiliforme. Se asocia a adenopatías retroauriculares, occipitales y cervicales que aparecen antes de la erupción. En ocasiones aparecen esplenomegalia, artralgias y en el laboratorio se observa leucopenia. En caso de duda diagnóstica, la presencia de anticuerpos IgM para rubéola permite establecer una infección aguda. La eficacia y cobertura de la vacuna hace improbable este diagnóstico actualmente en la población femenina. No sólo rubéola se asocia a un posible síndrome de MI con exantema. La infección por VEB (especialmente ante exposición a ampicilina) y la primoinfección por VIH también pueden evolucionar con esta característica.

Hepatitis A. Esta infección mantiene aún su vigencia en Chile y podría plantearse en el diagnóstico diferencial de la MI en la fase prodrómica con fiebre, calofríos y cefalea. Esta infección se asocia a linfocitosis, la que es ocasionalmente atípica, sin embargo, se asocia a vómitos o náuseas y a grandes aumentos de las transaminasas no característicos en las causas tradicionales de MI. El diagnóstico se establece por métodos serológicos específicos.

Coxiella burnetti. Este agente podría plantearse ante un cuadro febril prolongado en pacientes expuestos por razones laborales a deposiciones, orina o tejido placentario de cabras u ovejas. El cuadro se asocia a cefalea, mialgias y calofríos. El diagnóstico se efectúa por métodos serológicos.

\section{Estrategia integrada de estudio ante pacientes con síndrome de MI}

La posibilidad de que el síndrome de MI pueda ser provocado por la primoinfección por VIH ha reducido las implicancias benignas tradicionalmente asociadas a este síndrome y el desarrollo de los métodos de laboratorio ha posibilitado mejorar las capacidades diagnósticas y definir causas precisas e infrecuentes en este síndrome. El resultado final de estos factores es la modificación desde una actitud pasiva hacia una estrategia de diagnóstico activo en este síndrome. El trabajo diagnóstico debe lograr identificar la causa final. El predominio de la infección por VEB obliga a descartar esta condición en primer lugar (Figura 2). Cuando esta condición no se puede demostrar debe buscarse activamente otras causas. 


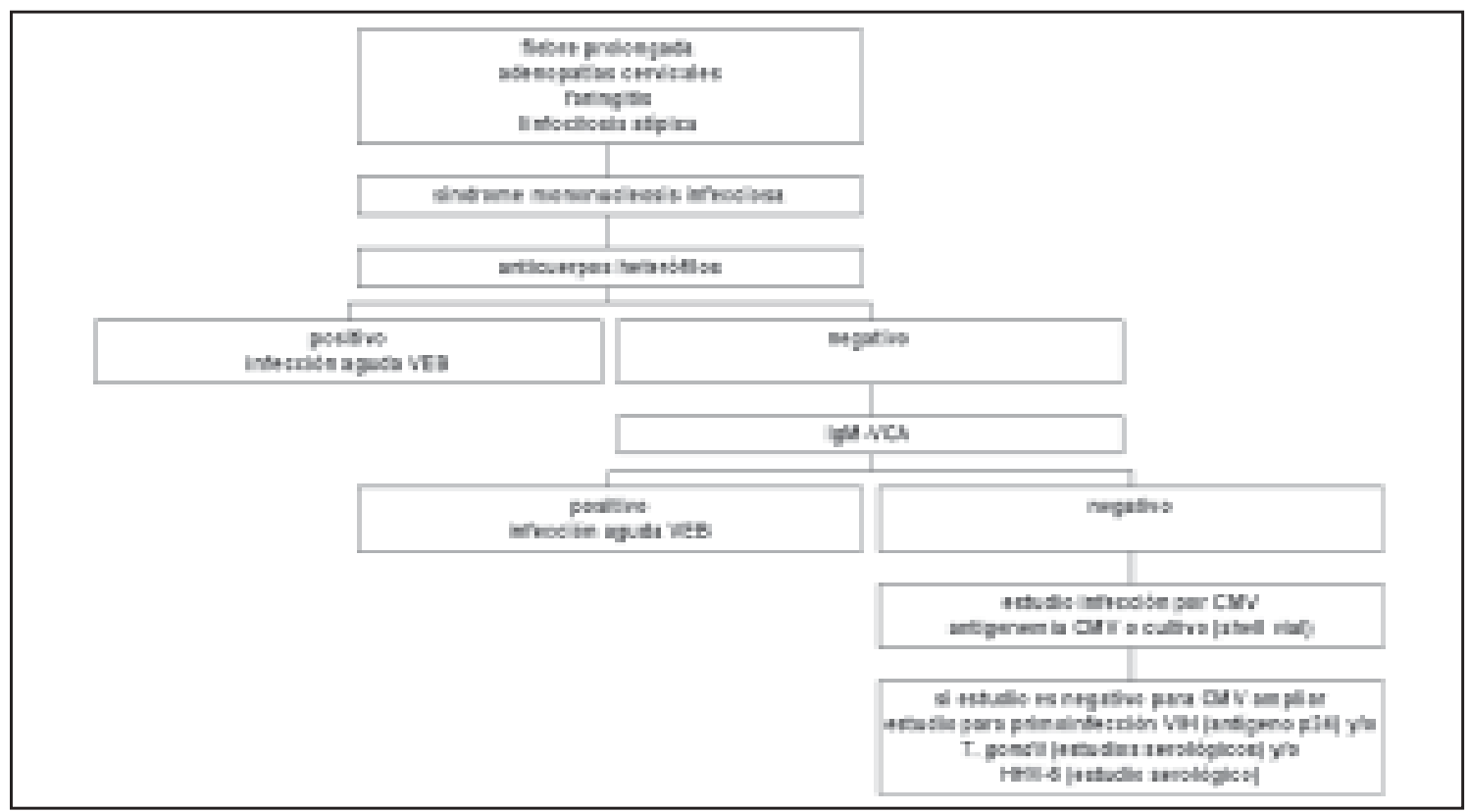

Figura 2. Algoritmo para el estudio del síndrome de mononucleosis.

\section{Bibliografía}

1.- Goldshall S E, Kirchner J T. Infectious Mononucleosis. Complexities of a common syndrome. Postgrad Med 2000; 107: 175-9, 183-4, 186.

2.- Bridgen M L, Au S, Thompson S, Bridgen S, Doyle P, Tsaparas D. Infectious mononucleosis in an outpatient population: diagnostic utility of 2 automated hematology analyzers and the sensitivity and specificity of Hoagland's criteria in heterophile positive patients. Arch Pathol Lab Med 1999; 123: 875-81.

3.- Linde A. Diagnosis of Epstein-Barr virus-related diseases. Scand J Infect Dis Suppl 1996; 100: 83-8.

4.- Strauss S E, Cohen J I, Tosato G, Meier J. EpsteinBarr virus infections: biology, pathogenesis, and management. Ann Intern Med 1993; 118: 45-8.

5.- Farley D R, Zietlow S P, Bannon M P, Farnell M B. Spontaneous rupture of the spleen due to infectious mononucleosis. Mayo Clin Proc 1992; 67: 846-53.

6.- Revello M G, Zavattoni M, Sarasini A, Percivalle E, Simoncini L, Gerna G. Human cytomegalovirus in blood of immunocompetent persons during primary infection: prognostic implications for pregnancy. J Infect Dis 1998; 177: 1170-5.

7.- Lesprit P, Scieux C, Lemann M, Carbonelle E, Modaï J,
Molina J M. Use of the cytomegalovirus (CMV) antigenemia assay for the rapid diagnosis of primary CMV infection in hospitalized adults. Clin Infect Dis 1998; 26: 646-50.

8.- Sepúlveda C, Thompson L, Castrillón M A, Hurtado C. Infección primaria por el VIH. Características clínicas y serológicas. Rev Méd Chile 1995; 123: 74-80.

9.- Larrondo M. Diagnóstico serológico de la infección por VIH. En: SIDA, tercera edición. Sepúlveda C, Afani A, (eds). Editorial Mediterráneo, Santiago, 2002, p 121-33.

10.- Irving W L, Cunningham A L. Serological diagnosis of infection with human herpesvirus type 6 . Br Med J 1990; 300: 156-9.

11.- Fica A. Influenza: Profilaxis mediante la inmunización activa. Rev Chil Infect 2001; 18: 133-41.

12.- Akerlind-Stopner B, Mufson M A. Respiratory virus. En: Specter S, Lancz G (eds). Clinical Virology Manual (second edition). Elsevier Science Publishing Company, New York, 1992. p 321-40.

13.- Fica A. Manejo de la faringoamigdalitis estreptocócica en pacientes adultos o adolescentes. Rev Chil Infect 2002; 19: 79-91.

14.- Departamento de Epidemiología, Ministerio de Salud. Rubéola. El Vigía, Boletín de Vigilancia Epidemiológica 1999; 2: 1-11.

Correspondencia:

Alberto Fica Cubillos

E-mail: afica@ns.hospital.uchile.cl 